\title{
Gain Control in the Electrosensory System Mediated by Descending Inputs to the Electrosensory Lateral Line Lobe
}

\author{
Joseph Bastian \\ Department of Zoology, University of Oklahoma, Norman, Oklahoma 73019
}

The electrosensory lateral line lobe (ELLL) of weakly electric fish, the primary electrosensory processing station, receives a large descending input from the midbrain in addition to the input from the electroreceptor afferents. The role of a major component of this descending input in determining the properties of ELLL output neurons was investigated. The descending input was reduced or eliminated by microinjections of the local anesthetic lidocaine or by small lesions. This treatment increased the responses of the ELLL output neurons to suprathreshold stimuli by about $300 \%$ and also increased the size of the neurons' receptive fields for moving electrolocation targets and the resolution with which they encode target distance. The neurons' threshold sensitivity and tuning to amplitude modulation frequency were unchanged by removal of the descending input. The results of this study show that this portion of the descending input to the ELLL normally mediates an inhibition that controls the responsiveness of ELLL output neurons. This descending input could function as a gain control mechanism, allowing the animal to modulate the sensitivity of the electrosensory system in response to changing environmental conditions.

Descending connections within the nervous system are a widespread but very poorly understood neural circuit phenomenon. Such connections are commonly found in sensory processing circuitry, where information from higher centers projects to lower stages in the processing hierarchy or to the sensory apparatus itself. Progress toward an understanding of the general significance of descending connections within sensory processing systems will be facilitated by studies of relatively simple systems in which patterns of natural stimuli important to the animal are known, the neuroanatomy of the structures involved in the feedback loops is known, and robust effects of the descending influences can be demonstrated. The electrosensory system of weakly electric fish has proved to bc a particularly attractive system for studies of sensory processing mechanisms in general. This study provides an initial description of the role of descending inputs in shaping the responses of neurons within the primary electrosensory processing area, the electrosensory lateral line lobe (ELLL).

Weakly electric fish generate an electric field around their body by means of an electric organ located in the elongate tail. These animals also possess specialized sense organs, tuberous electroreceptors, which sense the voltage that develops across the skin due to the electric organ discharge (EOD). The electroreceptors are derivatives of the lateral line system, and they are tuned to the frequency of the EOD (Hopkins, 1976). The electric organ of the animal used in this study, Apteronotus leptorhyn-

Received June 10, 1985; revised Aug. 14, 1985; accepted Aug. 21, 1985.

This work was supported by National Institutes of Health Grant NS12337.

Correspondence should be addressed to Dr. Bastian.

Copyright (C) 1986 Society for Neuroscience $0270-6474 / 86 / 020553-10 \$ 02.00 / 0$ chus, is composed of modified spinal motorneurons, and the discharge is a quasisinusoidal waveform that has a fundamental frequency of between about 700 and $1000 \mathrm{~Hz}$, depending on the individual. This electrosensory system provides the animals with the ability to sense objects in the environment whose electrical impedance differs from the surrounding water and to perceive the discharges of other electric fish. A large amount of physiological and behavioral information is available regarding the operation of this sensory system (for reviews, see Bullock, 1982; Heiligenberg, 1983; Heiligenberg and Bastian, 1984; Hopkins, 1983). The neuroanatomy of the electrosensory system is also being thoroughly studied, and the available anatomical information greatly facilitates the design and interpretation of physiological and behavioral studies.

The ELLL is the primary CNS processing station for electrosensory information, and the anatomy of this region as well as its afferent and efferent connections have been studied both at the light- and electron-microscopic level (Maler, 1979; Maler et al., 1974, 1981, 1982). The ELLL receives the projection of the electroreceptor afferents from the ipsilateral side of the body, and its efferents project predominantly to the contralateral midbrain torus semicircularis and nucleus praeeminentialis. The latter structure also receives a complex input from the torus semicircularis. The majority of the output of the n. praeeminentialis projects back, bilaterally, to the ELLL, forming a feedback loop (Sas and Maler, 1983). The anatomy of this descending projection suggests that it should significantly influence the behavior of a number of ELLL interneurons, as well as two of the categories of the ELLL output neurons.

Physiological studies of the ELLL have described the responses of ELLL neurons to modulations in the amplitude of the EOD field caused by large short-circuiting stimuli or by the imposition of additional fields (Bastian and Heiligenberg, 1980; Enger and Szabo, 1965; Scheich, 1977). The frequency-response characteristics of two catcgorics of ELLL output ncurons, Eand I-cells, along with their responses to a variety of electrolocation targets moving relative to the fish, have also been described, and receptive field sizes and geometries have been defined (Bastian, 1981b). The anatomical identity of the ELLL E- and Icells has also been determined by intracellular recording and HRP injection (Saunders and Bastian, 1984). This large amount of information about the structure and function of the ELLL provides a good background for comparison with the results of studies in which components of the descending neural circuits involving the ELLL are manipulated.

\section{Materials and Methods}

The gymnotiform fish $A$. leptorhynchus was used exclusively in this study. Surgery and recording techniques were the same as described previously (Bastian, 1975). The animals were suspended in a tank measuring $45 \times 45 \times 15 \mathrm{~cm}$ deep. Water conductivity was maintained at $10 \mathrm{k} \Omega \cdot \mathrm{cm}$ and temperature was $25 \pm 1^{\circ} \mathrm{C}$. The animal's EOD field was measured via electrodes placed near the head and tail, and this signal 


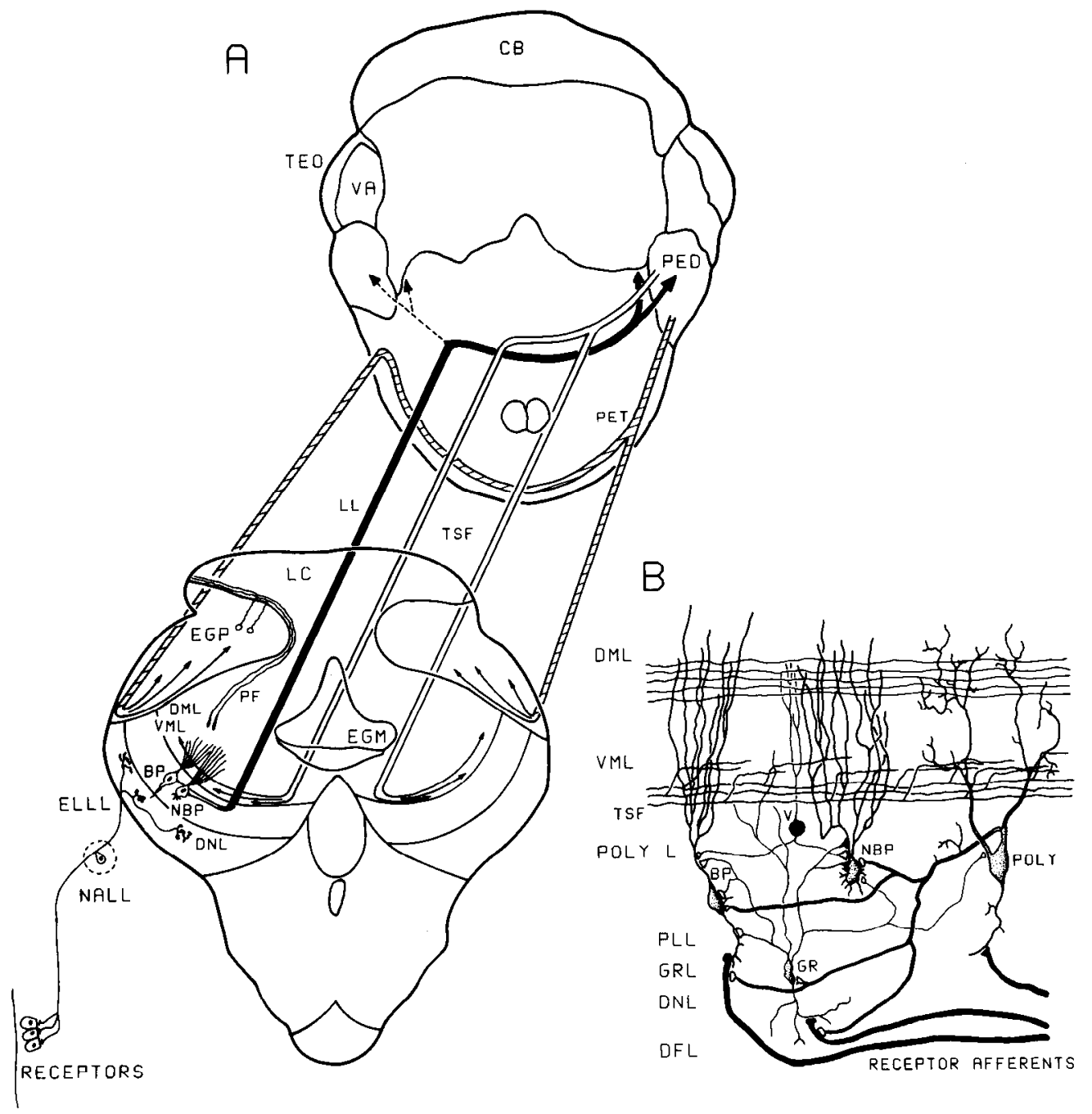

Figure 1. Afferent and efferent connections of the ELLL $(A)$ and a simplified diagram of the circuitry of the $\operatorname{ELLL}(B) . B P$, basilar pyramidal cell; $C B$, cerebellum; $D F L$, deep fiber layer; $D N L$, deep neuropil layer; $D M L$, dorsal molecular layer; $E L L L$, electrosensory lateral line lobe; $E G M$, medial eminentia granularis; $E G P$, posterior eminentia granularis; $G R$, granule cell; $G R L$, granule cell layer; $L C$, caudal lobe of the cerebellum; $L L$, lateral lemniscus; $N A L L$, anterior lateral line nerve; $N B P$, nonbasilar pyramidal cell; $P E D$, dorsal nucleus praeeminentialis; $P F$, parallel fibers; $P E T$, praeeminential electrosensory tract; $P O L Y$, polymorphic cell; $P O L Y$ $L$, polymorphic layer; $T E O$, optic tectum; $T S F$, stratum fibrosum; $V$, neurons of the ventral molecular layer; $V A$, valvula of the cerebellum; $V M L$, ventral molecular layer. was led to an analog multiplier circuit. A modulation signal, $100 \mathrm{msec}$ square pulse or continuous sinusoidal signal of various frequencies, was also led to the multiplier. This device then produced an output that was an EOD waveform, amplitude modulated in either a square wave or sinusoidal manner. This signal was applied to the bath via electrodes $22 \mathrm{~cm}$ lateral to either side of the fish. The resultant field experienced by the fish was the sum of the animal's normal EOD plus the amplitude modulated EOD waveform. Stimulus intensity was controlled by a Hewlett-Packard 350D step attenuator, the amplitude of the stimulus field was adjusted so that $0 \mathrm{~dB}$ corresponded to a $2 \mathrm{mV} / \mathrm{cm}$ change in total field measured perpendicular to the body surface just lateral to the animal's pectoral fin. Undisturbed electric field amplitudes measured in this region ranged from approximately 4 to $6 \mathrm{mV} / \mathrm{cm}$ depending on the size of the fish.

Electrolocation targets were moved parallel to the long axis at various lateral displacements from the animal by an $x-y$ positioning device; target velocity was $4 \mathrm{~cm} / \mathrm{sec}$. Single unit activity was collected by an on-line computer system that produced histograms relating a cell's activity to the object's position. Histogram bin width was $50 \mathrm{msec}$; this corresponds to a movement of $2.0 \mathrm{~mm}$ parallel to the long axis of the fish, and the minimum change in lateral distance between the fish and the target was $2.5 \mathrm{~mm}$. Separate histograms were compiled for opposite directions of target movement. Typically, the responses to seven replicates of each movement cycle were summed and the arrays of data describing a cell's responses to a series of target movements were filtered by three passes of a simple digital filter; each bin value $X(j)$ was set equal to $[X(j-1)+2 X(j)+X(j+1)] / 4$. The columns and rows of the arrays were filtered. This procedure reduced the random variation in the responses but did not significantly alter the amplitude or the shape of the major peaks and valleys. The data arrays were also analyzed via a contour-mapping procedure. This results in plots of iso-spike-rate contours, and the areas of these were measured to assess receptive field sizes for moving electrolocation targets.

The descending input to the ELLL was manipulated in two ways. Microinjection of 100-500 nl of a $2 \%$ solution of lidocaine $\mathrm{HCl}$ was used to reversibly block the tract carrying a major component of the descending input to the ELLL. This procedure was reversible and was only sufficient for short-term modifications of the feedback connections. This same component of the descending circuitry was lesioned when long-term studies were to be made of cells' responses without this descending input.

\section{Results}

Three categories of ELLL neurons carry the output from this structure to the midbrain electrosensory processing areas. One category, the spherical cells, relays information about the timing of each cycle of the EOD, and these project exclusively to lamina 6 of the contralateral dorsal torus semicircularis. The remaining two categories, the basilar and nonbasilar pyramidal cells, project predominantly contralaterally, with minor ipsilateral connections, to the dorsal praeeminential nucleus (PED) and to laminae 3, 5, 7, and 8c, d of the dorsal torus semicircularis (Maler et al., 1982). The basilar pyramidal cells, also known as E-cells, respond to increased electrosensory stimulation with an increase in firing frequency and the nonbasilar cells, I-cells, respond to this same stimulus with a reduction in activity (Bastian, 1981b; Enger and Szabo, 1965). Intracellular recording followed by single cell horseradish peroxidase staining has demonstrated the equivalence of the physiologically defined $E$ - and 
I-cells and the anatomically defined basilar and nonbasilar cells (Saunders and Bastian, 1984).

Figure $1 A$ summarizes the connections between the ELLL and the midbrain electrosensory processing regions, and Figure $1 B$ is a simplified diagram of the anatomy of the ELLL itself modified from Maler et al. (1981). The spherical cells of the ELLL and the $T$-receptor afferents that communicate with them are omitted. Probability coder or P-receptor afferents enter the ELLL, forming the deep fiber layer; these axons then make excitatory chemical synapses (filled terminals) with basilar pyramidal cells, granule cells, and polymorphic cells, as well as with the very rare ovoid cells (not shown). The excitatory receptor afferent input to the basilar pyramidal cells is believed to account for their increased activity in response to increased electrosensory stimulation. The granule cells make probable inhibitory chemical synapses (open terminals) with the nonbasilar pyramidal cells, the basilar pyramids, and the polymorphic cclls. The nonbasilar cells receive no direct electroreceptor afferent input; instead they are driven by granule cells. The presumed inhibitory nature of the granule cell to nonbasilar cell chemical synapse is thought to account for their reduction in activity, owing to increased electroreceptor afferent input. The granule cells also make electrical synapses with the nonbasilar pyramidal cells (filled attached terminals). The polymorphic cells receive a direct input from the electroreceptor afferents and make probable inhibitory synapses with all other cell types shown, except neurons of the ventral molecular layer. The polymorphic cells also make axoaxonic inhibitory synapses with a subset of the receptor afferent terminals.

The pyramidal cells, polymorphic cells, neurons of the ventral molecular layer, and a subset of the granule cells, type 2 granule cells, have large apical dendritic trees. These ramify and make numerous synaptic contacts with the fibers of the dorsal and ventral molecular layers of the ELLL. The ventral molecular layer consists of fibers of tractus stratum fibrosum which is one of the two descending output pathways of the nucleus praeeminentialis. The tractum stratum fibrosum (Fig. $1 A$ ) is a bilateral descending pathway that enters the ELLL rostromedially and runs caudally, giving off collaterals that run transversely across most of the extent of the ventral molecular layer (Maler, 1979). The dorsal molecular layer consists of parallel fibers originating from the granule cells of the overlying posterior eminentia granularis (EGP) of the caudal lobe of the cerebellum. These fibers enter the ELLL dorsally and run ventrally and caudally; hence, their orientation is approximately orthogonal to the fibers of the ventral molecular layer. A major source of the input to the posterior eminentia granularis descends from the ipsilateral and contralateral n. praeeminentialis (Sas and Maler, 1983). This descending input is carried by the praeeminential electrosensory tract (PET; Fig. $1 A$ ), and this tract is clearly visible as it courses along the lateral edge of the posterior eminentia granularis above the ELLL. The role of this latter component of the descending input in shaping the responses of the ELLL is the focus of this study. The fortuitous anatomy allows either reversible or irreversible interruption of this tract via local anesthetics or lesions.

\section{Responses to stepwise changes in EOD amplitude}

E-cells in a normal fish respond to a stepwise increase in EOD amplitude with a short-latency increase in firing frequency that adapts rapidly. The rasters and poststimulus time histogram of Figure $2 A$ show a typical E-cell response to a $2 \mathrm{mV} / \mathrm{cm}$ increase in EOD amplitude. The spontaneous firing frequency of this cell averaged $23.9 \mathrm{spikes} / \mathrm{sec}$, and this increased to $320.0 \mathrm{spikes} / \mathrm{sec}$ during the first $10 \mathrm{msec}$ of the response. The response adapted rapidly, the time constant for adaptation was $37 \mathrm{msec}$, and spike frequency averaged over the duration of the stimulus period was $88.0 \mathrm{spikes} / \mathrm{sec}$. In a sample of 32 normal E-cells, spontaneous activity, measured over the $50 \mathrm{msec}$ period prior to each stim-

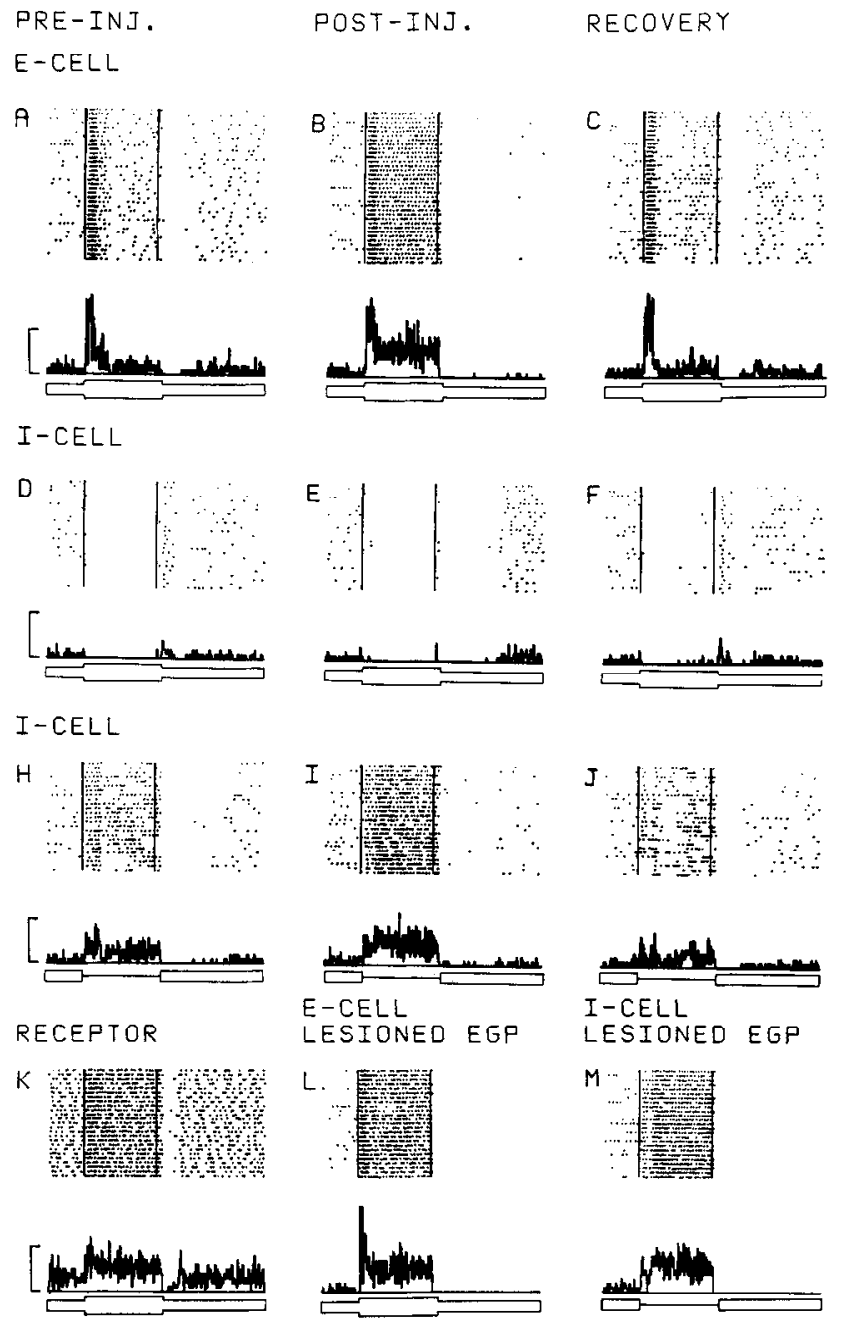

Figure 2. Responses of ELLL E- and I-cells to $100 \mathrm{msec}$ stepwise changes in electrosensory stimulus amplitude. Histograms summarize data shown in each raster: histogram bin width, $1 \mathrm{msec}$; vertical calibration, 10 spikes/bin. The envelope of the stimulus waveform is shown below each raster. $A-C$, Responses of an E-cell to a $2 \mathrm{mV} / \mathrm{cm}$ increase in EOD amplitude before, during, and after recovery from lidocaine injected into the PET. $D-F$, Responses of an I-cell under the same conditions as $A-C$. $H-J$, Responses of the same I-cell to a $2 \mathrm{mV} / \mathrm{cm}$ decrease in EOD amplitude before, during, and after PET anesthesia. $K$, Electroreceptor afferent responses to a $2 \mathrm{mV} / \mathrm{cm}$ increase in EOD amplitude. $L$ and $M$, Responses of an E- and I-cell, after EGP lesioning, to a $2 \mathrm{mV} / \mathrm{cm}$ increase and $2 \mathrm{mV} / \mathrm{cm}$ decrease in EOD amplitude.

ulus, averaged $18.0 \mathrm{spikes} / \mathrm{sec}(\mathrm{SE}=1.66)$, and firing frequency during the first $10 \mathrm{msec}$ of the response averaged 209.9 spikes/ $\sec (\mathrm{SE}=12.9)$. Mean frequency during the entire stimulus period averaged 81.0 spikes/sec $(S E=7.50)$, and time constants of adaptation, time for response decay to $37 \%$ of its maximum, averaged $24.5 \mathrm{msec}(\mathrm{SE}=2.8$ ).

A micropipette having a tip diameter of about $10 \mu \mathrm{m}$ was inserted into the praeeminential electrosensory tract while recording from the E-cell of Figure $2 A$. Injection of between 100 and $500 \mathrm{nl}$ of a lidocaine solution into this tract altered the responses of E-cells, as shown in Figure $2 B$. The initial highfrequency response no longer completely adapts, spike frequency is significantly enhanced throughout the stimulus period, and the reduction in spike frequency following the end of the stimulus is prolonged. The first injection attempt was not always successful; the pipette must be placed in an appropriate region of the tract for the drug to affect a given ELLL cell. If the injection 

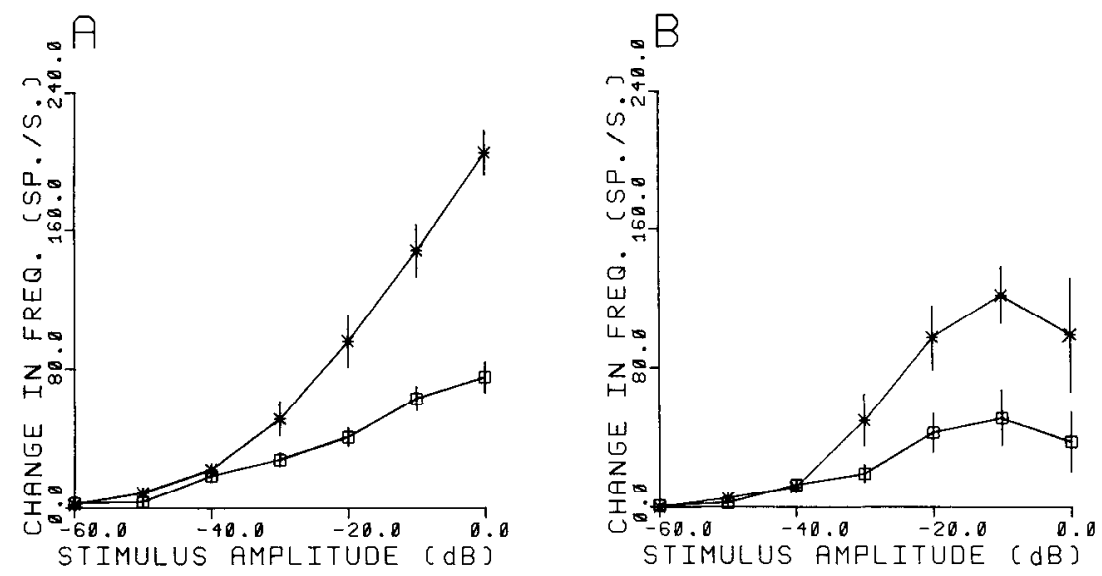

Figure 3. Changes in E- and I-cell firing frequency as a function of stimulus amplitude in normal animals and those with the EGP lesioned. $A$, E-cells from normal fish (squares) increase firing frequency at a rate of $1.5 \mathrm{spikes} / \mathrm{sec} / \mathrm{dB}$ increase in stimulus amplitude. This slope was determined from the best-fit line to responses to stimuli between -40 and $0 \mathrm{~dB} ; 0 \mathrm{~dB}$ corresponds to a $2 \mathrm{mV} / \mathrm{cm}$ increase in EOD amplitude. Symbols indicate the mean response size $(n=15)$ and the vertical bars indicate $\pm 1 \mathrm{SE}$ in this and all subsequent figures. E-cell responses in fish with EGP lesions (asterisks) increase at a rate of $4.6 \mathrm{spikes} / \mathrm{sec} / \mathrm{dB}$ increase in EOD amplitude. This slope was determined from a best-fit line to the same range of data, $n=12$. $B$, I-cell responses increase at a rate of $1.4 \mathrm{spikes} / \mathrm{sec} / \mathrm{dB}$ of decreasing stimulus amplitude in normal fish (squares, $n=9)$ and at a rate of $3.8 \mathrm{spikes} / \mathrm{sec} / \mathrm{dB}$ in fish with EGP lesions (asterisks, $n=6$ ). These slopes were determined from best-fit lines to data between - 40 and $-10 \mathrm{~dB} ; 0 \mathrm{~dB}$ corresponds to a $2 \mathrm{mV} / \mathrm{cm}$ decrease in EOD amplitude.

failed, the pipette was withdrawn, and, after about $10 \mathrm{~min}$, a second injection was made. Successful injections always caused the same alteration in the E-cells' responses. Figure $2 C$ shows the response of this same E-cell approximately 8 min after the lidocaine injection. The effect of the drug is completely reversible, and the cell's response after recovery is not significantly different from that prior to anesthesia of the PET.

An alternate method, which allowed long-term studies of single cells, was also used to remove this component of the descending input to the ELLL. The posterior eminentia granularis and portions of the PET were electrolytically lesioned with a metal-filled micropipctte having a tip diamcter of about $20 \mu \mathrm{m}$. After making a pattern of small lesions, the majority of the granule cell mass could be dissected away. This procedure produced minimal damage to the underlying ELLL, and these lesions usually included approximately $80 \%$ of the rostrocaudal extent of the EGP. After this operation, the responses of E-cells were identical to those of E-cells after lidocaine injection into the PET (compare Fig. 2, $B$ with $L$ ).

E-cell spontaneous activity was decreased, but not significantly, as a result of either PET anesthesia or ablation of the EGP: It averaged $15.2 \mathrm{spikes} / \mathrm{sec}(\mathrm{SE}-1.55)$ for a sample of 27 cells that included results from both treatments. The initial response to the stimulus, response during the first $10 \mathrm{msec}$, increased to $326.9 \mathrm{spikes} / \mathrm{sec}(\mathrm{SE}=12.44, n=27)$, and this is significantly greater than the 209.9 spikes/sec seen in the normal situation ( $p<0.001$, as judged by a $t$ test). Likewise, the average frequency during the stimulus period increased to 204.7 spikes/ $\sec (\mathrm{SE}=8.74, n=27)$, and this increase is also significant $(p<$ $0.001)$. The increased activity over the duration of the stimulus period also increased the mean adaptation time constant to 50.5 msec $(\mathrm{SE}=3.8, p<0.001)$. Removal of this component of the descending input to the ELLL alters E-cell responses so that they more closely resemble the responses of single electroreceptor afferents (compare Fig. 2, $B$ and $L$, with $K$ ). No significant differences were found between any of these measurements contingent on the method used to remove descending input to the dorsal molecular layer.

I-cells respond to an increase in electrosensory stimulation with a short-latency decrease in action potential frequency. The cells are usually silenced for the duration of the stimulus when stimuli of $2 \mathrm{mV} / \mathrm{cm}$ are used, and a burst of activity usually follows stimulus cessation (Fig. 2D). The degree and duration of the reduction in spike frequency is graded with stimulus strength. Anesthesia of the PET reduces, or removes, the "off" response and prolongs the inhibition so that it outlasts the stimulus (Fig. 2E). I-cells recover completely from this treatment, as shown in Figure $2 F$. I-cells respond to reductions in EOD amplitude with an increase in activity. This stimulus is preferred, since increases in activity can be more accurately measured over wider ranges of stimulus intensity. Figure $2, H-J$, shows an I-cell's responses to a $2 \mathrm{mV} / \mathrm{cm}$ reduction in EOD amplitude before, during, and after PET anesthesia. Responses are significantly augmented by either PET anesthesia or by EGP Icsions (comparc Fig. 2, $I$ with $M$ ). I-cell spike frequency during the response to decreased EOD amplitude increased from 62.9 spikes/sec ( $\mathrm{SE}=11.1, n=22$ ) for normal fish to 130.6 spikes/ sec ( $\mathrm{SE}=19.3, n=17$ ) for animals with the descending input modified by one of these two techniques $(p<0.01 ; t$ test). As in the case of E-cells, spontaneous activity was slightly reduced by this treatment: It averaged $21.1 \mathrm{spikes} / \mathrm{sec}(\mathrm{SE}=2.57, n=$ 22) in normal fish and 18.4 spikes/sec $(\mathrm{SE}=2.67, n=17)$ in fish that had the PET anesthetized or the EGP lesioned.

\section{Effects of stimulus amplitude and frequency}

The lesion technique was used in experiments in which it was necessary to record the responses of a single cell over a long time period. Since this technique irreversibly removes input to the dorsal molecular layer, the average responses of a number of E- and I-cells in normal and lesioned fish were compared. Selected individual data points were also taken using PET anesthesia and intact fish in order to determine if any result was contingent on the method used to remove the descending input. No differences were seen. Figure $3, A$ and $B$, shows the changes in average spike frequency for $\mathrm{E}$ - and I-cells in fish with normal and lesioned EGPs as a function of stimulus intensity. Change in frequency is the average frequency during the stimulus minus that prior to the stimulus. Removal of the descending input by either means increased the slopes of the relationships between stimulus amplitude and E- and I-cell responses; thresholds, however, were not significantly affected. E-cell responses in normal fish increased at a rate of about $1.5 \mathrm{spikes} / \mathrm{sec} / \mathrm{dB}$, but when the EGP was lesioned the responses increased to 4.6 spikes $/ \mathrm{sec} / \mathrm{dB}$ of increased stimulus amplitude. I-cells were studied by stimulating the fish with FOD reductions rather than increases, and their responses changed in a similar fashion, at least over part 


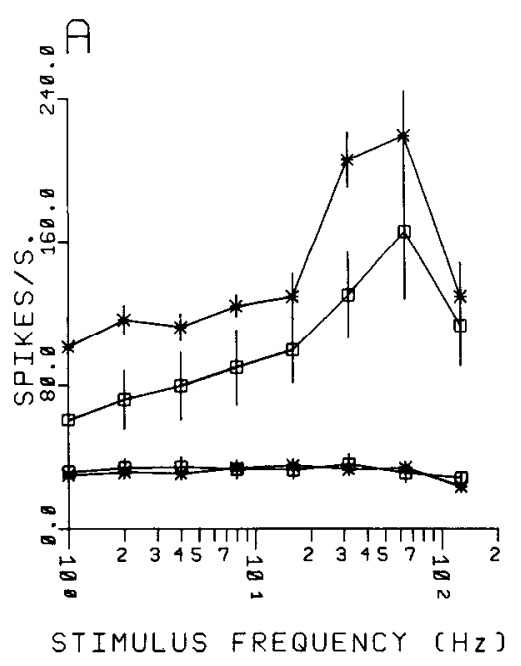

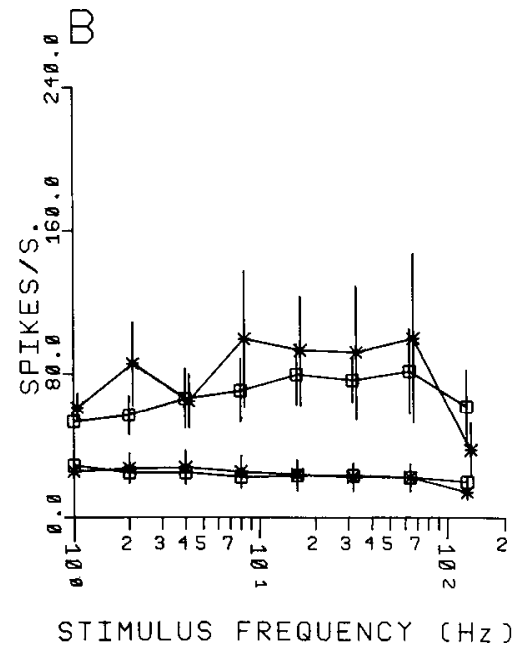

Figure 4. E- and I-cell responses in normal fish (squares) and in those with EGP lesions (asterisks) to various frequency $2 \mathrm{mV} / \mathrm{cm}$ sinsusoidal AMs of the EOD. A, Lowest set of traces shows mean firing frequency of E-cells from normal and lesioned fish determined from 1000 consecutive spikes at the indicated stimulus frequencies. The upper set of traces shows the average difference between the maximum and the minimum spike frequency seen within the stimulus cycle at each stimulus frequency. Sample sizes: $n=6$ for normal and $n=5$ for lesioned fish. $B$, Results of the same experiment for seven I-cells from normal fish and for five I-cells from lesioned fish. of the range of stimuli used. I-cell responses to stimuli between -40 and $-10 \mathrm{~dB}$ increased by about $1.4 \mathrm{spikes} / \mathrm{sec} / \mathrm{dB}$ reduction in EOD amplitude in normal animals, and this increased to 3.8 in lesioned fish. I-cell responses plateaued with the stronger stimuli. This is simply due to the fact that the stimulus was a reduction in EOD amplitude. The receptor afferents signal this stimulus with reduced spike frequency, and the granule cells driven by these afferents will also reduce their frequency. As soon as the responses of either of these cell types approaches a reduction to zero, I-cell responses should plateau.

An earlier study indicated that both the E- and I-cells show differential sensitivity to various frequency EOD amplitude modulations (AMs) (Bastian, 1981b). Figure 4, $A$ and $B$, summarizes the responses of a sample of E- and I-cells to continuous $2 \mathrm{mV} / \mathrm{cm}$ sinusoidal AMs of the EOD. The lower pair of lines in each plot shows the average spike frequency measured over the total time the stimulus was on. Neither cell type shows any changes in this average spike frequency due to different AM frequency or as a result of EGP lesioning. The upper traces show the maximum change in spike frequency that occurs within the AM cycle. These cells respond to AMs by restructuring the spike train, that is, the cells tend to fire at preferred phases within the AM cycle. Increased clustering of spikes then increases the change in spike frequency seen within the cycle. E-cells tend to fire at the peak of the AM, a tendency that increases with increasing AM frequency, reaching a maximum at between 64 and 128 $\mathrm{Hz}$. This reflects the AM frequency preference described for receptor afferents (Bastian, 1981a). I-cells fire near the minimum of the AM cycle, and as a group, show much less differential sensitivity to AMs of different frequencies. There is large individual variation, and some I-cells display more pronounced sensitivity to lower AM frequencies than is shown by these averaged responses (Bastian, 1981b). EGP lesions did not alter the AM frequency selectivity of either the E- or I-cells. Removal of the descending input to the dorsal molecular layer simply increased the sensitivity of both cell types to AMs of most frequencies.

\section{Responses of ELLL cells to moving electrolocation targets}

Previous studies have described the responses of ELLL E- and I-cells to various moving electrolocation targets (Bastian, $1981 \mathrm{~b}$; Enger and Szabo, 1965). E-cells typically respond to objects having a higher conductivity than the surrounding water, such as metal objects, with an increase in activity as the target passes the area of skin containing the electroreceptor afferents that converge on the E-cell. This excitatory response is usually surrounded by regions within which the target causes weaker reductions in activity. These reductions in spike frequency are partially due to the pattern of the changes in EOD amplitude resulting from the presence of the electrolocation target (Bastian, 1981a; Heiligenberg, 1975; Hoshimiya et al., 1980), partly due to the occurrence of receptor afferent and E-cell off responses (Fig. 2, $A, K$ ), and probably also due to lateral inhibitory mechanisms operating within the ELLL (Maler et al., 1981). I-cells respond oppositely to electrical conductors: Regions of inhibition are flanked by excitation, and I-cell responses to nonconducting electrolocation targets that cause reduced EOD amplitude are very similar to the E-cell responses to conductors.

Figure 5 shows typical responses of an E-cell to a $9 \mathrm{~mm}$ metal cylinder moved rostrally $(A I)$ and caudally $(A 2)$ along the fish prior to injection of lidocaine into the PET. The excitatory responses occur when the object passes just caudal to the operculum, and the peak changes in firing frequency are 55 and 32 spikes/sec for headward and tailward moving objects, respectively. These excitatory responses are bordered by small regions of reduced activity. Lidocaine injection into the PET changed this cell's responses to stepwise increases in EOD amplitude in the manner described previously; likewise, the responses to the moving electrolocation target were greatly increased. Peak changes in firing frequency increased to 111 and $125 \mathrm{spikes} / \mathrm{sec}$ (Fig. 5, B1 and $B 2$, respectively), and much larger regions of strong inhibition appeared bordering both sides of the excitatory response. Eight minutes after the lidocaine injection, the cell had recovered and the responses to the moving stimulus were approximately the same as those prior to the injection (Fig. 5 , $C 1$ and $C 2$ ). I-cells respond to the moving metal target with strong inhibition flanked by weaker excitation. These responses are also enhanced by the PET anesthesia, and when I-cells are studied with moving nonconducting targets, they respond with excitation flanked by inhibition.

The output from the $n$. praeeminentialis projects bilaterally to the ELLLs; that is, a given ELLL receives descending inputs from both the ipsi- and contralateral PED (see Fig. 1 $A$ ). The descending input may therefore include information originally encoded by electroreceptors on either side of the body. The stepwise changes in EOD amplitude used in this study were delivered transversely via electrodes on either side of the fish. This results in stimulus current entering the fish on onc sidc and exiting on the other; hence, electroreceptors on either side of the body will be stimulated oppositely. The moving electrolocation targets also stimuluate receptors on the side of the body contralateral to the target, but very weakly compared with the effect on receptors ipsilateral to the object's position. In order to determine the effect of electroreceptor input from the side of the body contralateral to the ELLL recorded from, the connection between the contralateral anterior lateral line nerve ganglion 
Figure 5. Responses of an E-cell to a $9 \mathrm{~mm}$ metal cylinder (solid circles) moving headward and tailward parallel to the long axis of the fish at a lateral distance of approximately 5 mm. $A 1$ and $A 2$, Responses prior to PET anesthesia. $B 1$ and $B 2$, Responses during PET anesthesia. $C I$ and $C 2$, Responses after recovery from PET anesthesia. Outlines of the fish and the stimulus object are correctly scaled to the length of the histograms; vertical calibrations of $A 2$ and $C I$ correspond to 100 spikes/sec and apply to all traces.

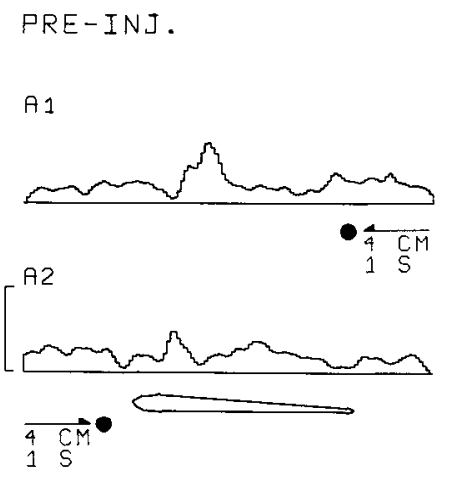

POST-INJ.

RECOVERY
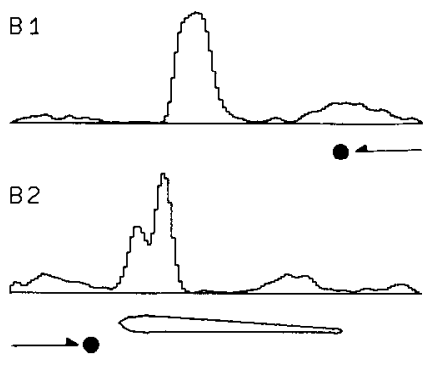

C 1

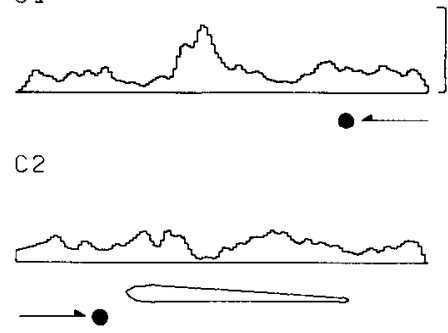

and the brain was severed. All electroreceptor input from the contralateral side was thereby eliminated. The data of Figure 5 were taken from a fish with the contralateral ganglion severed, and this procedure did not change the effects of PET anesthesia on responses to moving targets in any noticeable way. Responses of E- and I-cells to stepwise changes in EOD amplitude, with or without PFT anesthesia, were also unchanged by severing this ganglion. The major, physiologically effective, descending input to a given ELLL must therefore arise as a result of the efferents of that same ELLL activating circuitry, primarily in the contralateral PED.

The responses of E- and I-cells to electrolocation targets moving parallel to the long axis of the fish at a series of increasing lateral distances were also studied in normal fish and in animals with the EGP lesioned. Figure $6, A I$ and $A 2$, shows the families of histograms of an E-cell's activity recorded as a $12 \mathrm{~mm}$ metal cylinder moved in the headward and tailward directions at the indicated distances lateral to the fish. The main excitatory re-
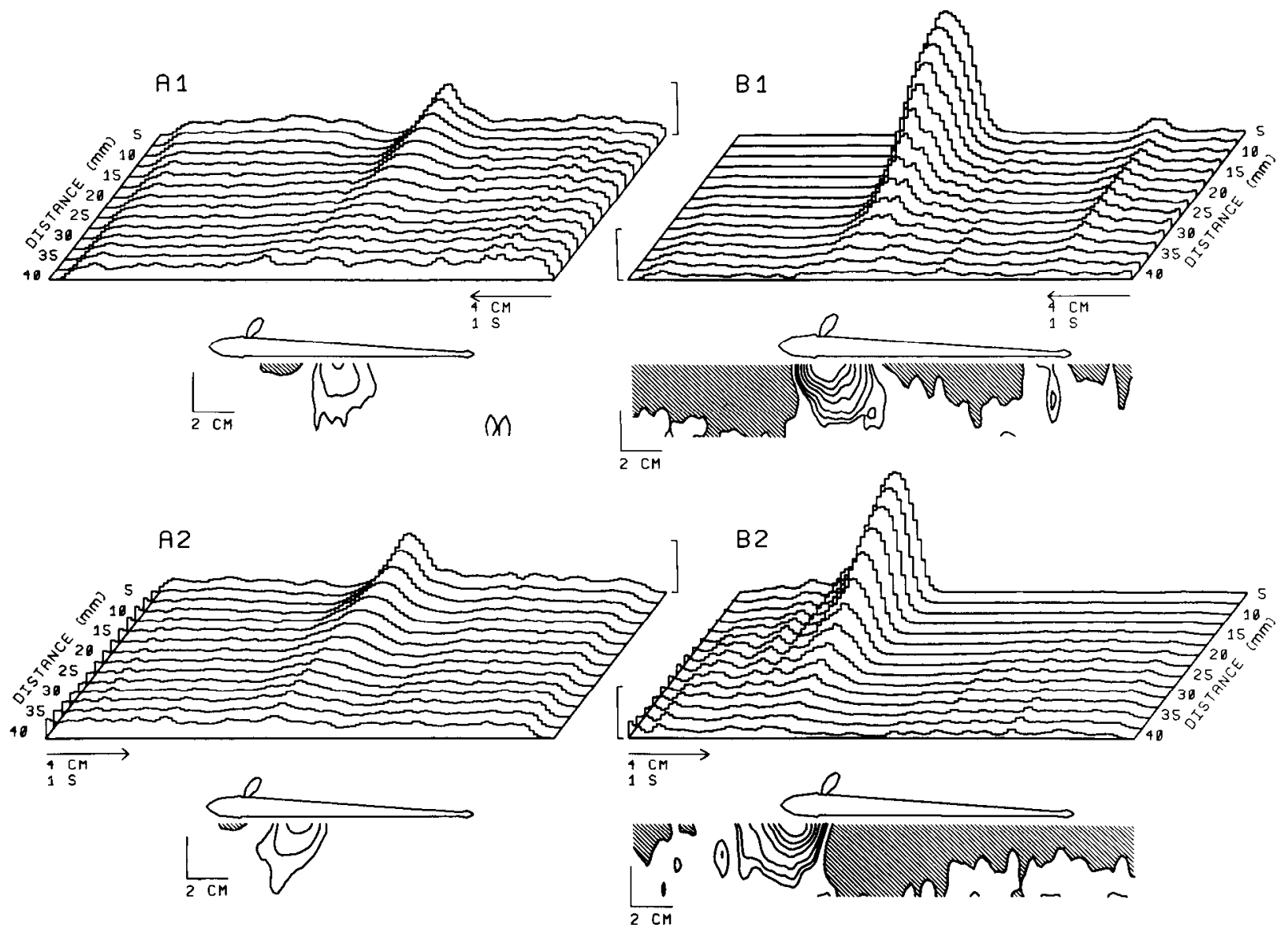

Figure 6. Responses of an E-cell from a normal and from an FGP-lesioned fish to a $12 \mathrm{~mm}$ metal cylinder moved parallel to the long axis of the fish at sequentially increasing lateral distances. $A 1$ and $A 2$, Responses to the headward and tailward movement of the target, respectively. Proceeding downward, each successive trace shows the cell's responses to the object moving $2.5 \mathrm{~mm}$ more lateral to the fish. The vertical calibration corresponds to $100 \mathrm{spikes} / \mathrm{sec}$. The series of contours below the outline of the fish shows the areas within which the moving object caused increases in spike frequency of 50,100 , and $200 \%$ of the cell's resting frequency $(29.7$ spikes/sec). The innermost contour outlines the area of the greatest frequency change. The small hatched region corresponds to the area within which the object caused decreases in activity equal to $50 \%$ of the cell's resting frequency. $B 1$ and $B 2$, Results of the same experiment for an E-cell from an animal with an EGP lesion. Proceeding from the outermost inward, the contours enclose areas within which the object caused increases of 50,100,200,400,600,800, and 1000\% of the cell's spontaneous frequency. The large hatched regions enclose areas within which the object reduced spike frequency to $50 \%$ of the cell's spontaneous discharge rate (17.6 spikes/sec). 

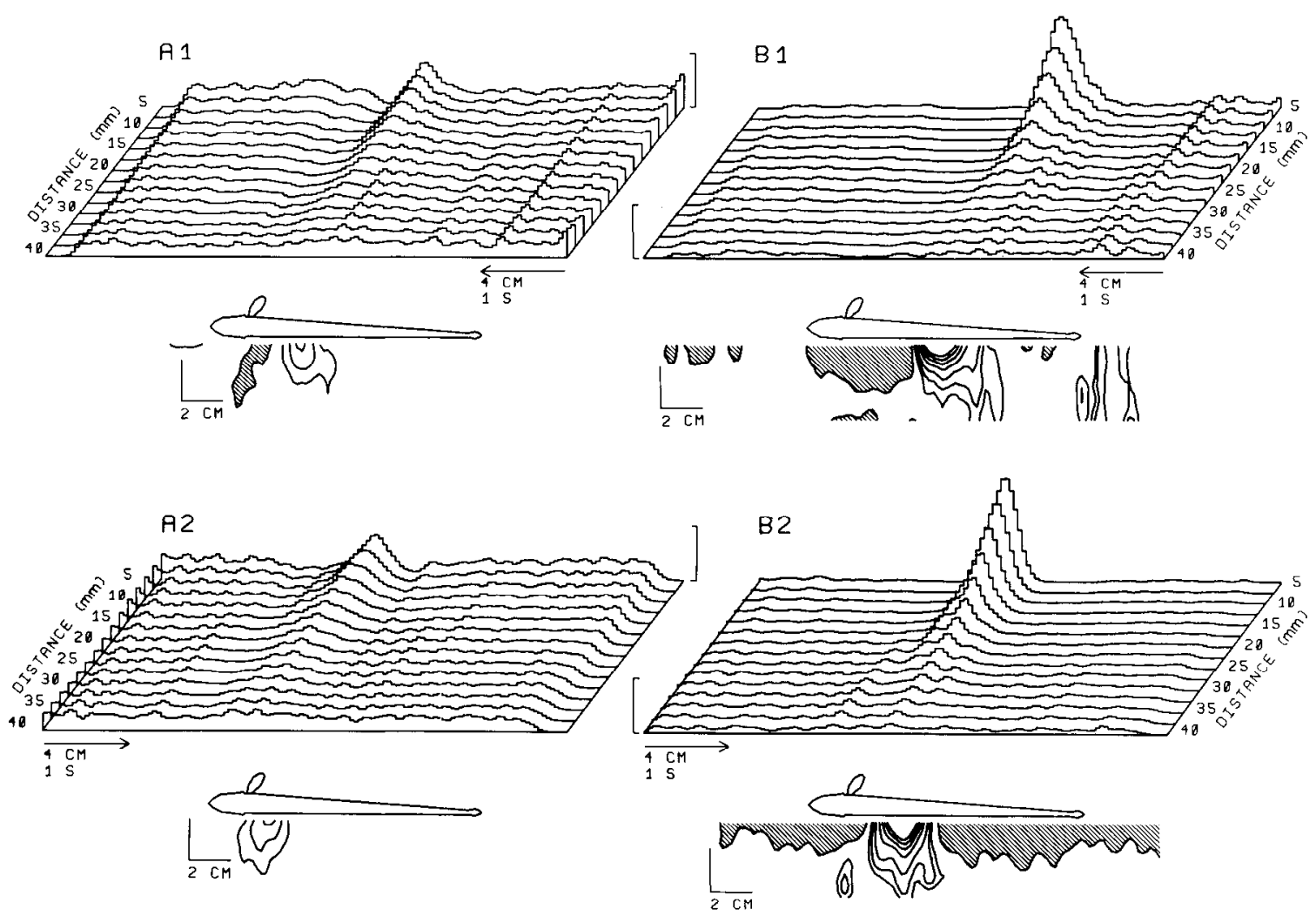

Figure 7. Responses of I-cells from normal and EGP-lesioned fish to a $12 \mathrm{~mm}$ plastic cylinder moving at sequentially increased lateral distances parallel to the long axis of the fish. $A I$ and $A 2$, Responses of an I-cell from a normal fish; contours enclose areas within which the object caused increases of 50,100 , and $163 \%$ and decreases of $50 \%$ (hatched area) of the cell's spontaneous firing rate (28.5 spikes/sec). $B 1$ and $B 2$, Responses from an EGP-lesioned fish; the contours enclose areas within which the electrolocation target caused increases of 50, 100, 200, 400, 600, 800, and $1000 \%$ and a decrease of $50 \%$ (hatched region) of the ccll's spontancous firing frequency $(9.6 \mathrm{spikes} / \mathrm{sec}$ ).

sponse, as well as the bordering inhibition, decreased with increasing object distance. Iso-rate contours were also computed from these data for increases in frequency of 50,100, and $200 \%$ and for reductions in frequency equal to $50 \%$ of the cell's resting frequency (hatched area). These are plotted to scale below the outline of each fish. The area of the $100 \%$ increase contour was measured for each experiment, and this area averaged $1.9 \mathrm{~cm}^{2}$ ( $\mathrm{SE}=0.254, n=10$ ) for pooled responses to headward and tailward moving targets. The reduction in E-cell responses due to increased lateral fish-target distance is summarized in Figure $8 A$ (squares) for $20 \mathrm{E}$-cells from normal fish. Responses decreased approximately linearly with the logarithm of distance out to about $25 \mathrm{~mm}$, and the slope of a best-fit line to data out to this distance was -41.0 .

Figure $6, B 1$ and $B 2$, shows the responses of another E-cell to this same stimulus but with the EGP lesioned. The amplitude as well as the spatial extent of the excitatory and the inhibitory responses were always significantly larger in animals with EGP lesions. The areas of the $100 \%$ spike frequency increase contours averaged $7 \mathrm{~cm}^{2}(\mathrm{SE}=0.494, n=12)$ for E-cell responses in fish with lesioned EGPs; this was significantly larger $(p<0.001)$ than the same measure for E-cells from normal fish. The relationship between object distance and E-cell response for animals with EGP lesions is shown in Figure $8 A$ (asterisks). EGP lesions not only increased response size at all fish-object distances, but also doubled the rate at which these larger responses decayed as a function of object distance, the slope of the best-fit line for data out to $25 \mathrm{~mm}$ bcing 82.0 . This means that the ability of the E-cells to resolve object distance is increased; that is, a given change in distance is signaled by a larger change in response size.
Similar experiments were done with I-cells, except that a 12 mm plastic cylinder was used as the stimulus. Figure $7, A$ and $B$, shows the results for a typical I-cell in a normal and in an EGP-lesioned fish. I-cell responses to the nonconducting stimulus were somewhat weaker, and the decay of the response as a function of object distance was slower, as had been shown earlier (Bastian, 1981b). The area of the $100 \%$ spike frequency increase contour averaged $1.26 \mathrm{~cm}^{2}(\mathrm{SE}=0.929, n=12)$. As in the case of E-cells, EGP lesions increased the average area of this contour by more than $300 \%$ - to $4.57 \mathrm{~cm}^{2}$ ( $\mathrm{SE}=0.589, n=$ 10 ). This treatment also increased the maximum average response size at all fish-object distances and increased the rate of decay of these responses as a function of distance by about $300 \%$ (Fig. $8 B$ ).

The excitatory responses of E- and I-cells seem to be similarly influenced by either of the techniques used to decrease the descending input to the ELLL dorsal molecular layer. E- and I-cell threshold for a change in firing frequency and AM frequency tuning characteristics are unchanged. The "gain" of the electrosensory system at this level and the receptive field areas for moving electrolocation targets are increased by from 200 to $300 \%$.

\section{Discussion}

The neuroanatomical studies of Maler et al. (1974) clearly showed that lesions of the posterior eminentia granularis, lobus caudalis granule cells, produced extensive degeneration of parallel fibers within the ELLL dorsal molecular layer. Similar lesions, or reversible blockade of the PET, which carries input to the EGP, results in increases in the responsiveness of ELLL E- and I-cells, as described here. Hence, the predominant influence of the dor- 

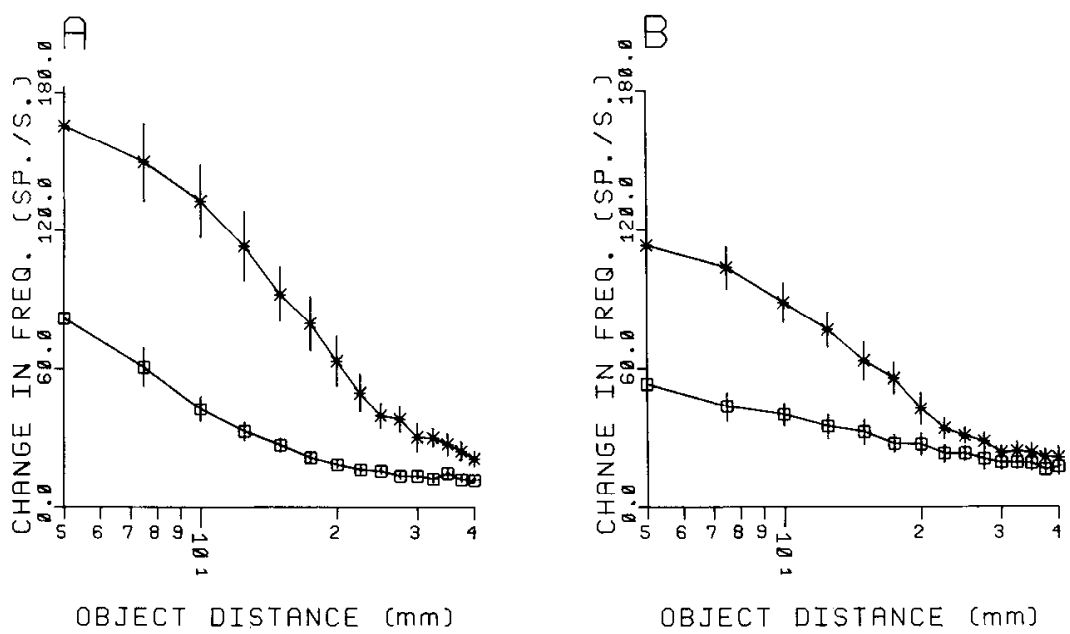

Figure 8. Summary of the decrease in F- and I-cell responses to moving electrolocation targets as a function of increased distance. $A$, Responses of E-cells from normal (squares) and lesioned (asterisks) fish. Response size was calculated as the difference between the highest spike frequency attained at a given object distance, mean of 5 consecutive bins, and the cell's spontaneous frequency. Vertical bars indicate \pm 1 SE; $n=18$ for normal fish and 8 for lesioned fish. The best-fit lines for these data, calculated out to a distance of $25 \mathrm{~mm}$, are $Y=143.0-41.5 \ln X$ and $Y=$ $310.5-81.9 \ln X$ for data from normal and lesioned fish, respectively. $B$, Results of a similar set of experiments done with I-cells. A 12 mm plastic cylinder was used rather than metal for I-cells; $n=7$ for normal fish and 8 for lesioned animals. Best-fit lines, computed for data out to a distance of $25 \mathrm{~mm}$, are $Y=82.7-18.8 \ln X$ and $Y=209.6-54.7 \ln X$ for results from normal and lesioned animals, respectively.

sal molecular layer activity on the ELLL output must be inhibitory. This is somewhat surprising in view of the large size of the E- and I-cell dendritic trees and the vast number of excitatory parallel fiber synapses on these (Maler et al., 1981). This finding suggests that the ELLL interneurons must be extremely important in mediating the descending input's influence on the ELLL's output.

\section{E-cell responses}

The fibers of the dorsal molecular layer are described as being morphologically identical to cerebellar parallel fibers (Maler et al., 1981). This, along with Maler's ultrastructural analysis of parallel fiber synapses, indicates that they are exclusively excitatory. Reduced parallel fiber activity due to PET anesthesia or EGP lesions is, therefore, not expected to directly increase E-cell responsiveness. Reductions in this input to the E-cells should have the opposite effect. A more likely source of the increased E-cell responsiveness would be via reductions in the activity of ELLL inhibitory interneurons. Neurons of the ventral molecular layer (V in Fig. $1 B$ ) receive their input exclusively from the parallel fibers of the dorsal and ventral molecular layers, and these form inhibitory synapses with the basilar pyramidal cells. Type II granule cells as well as polymorphic cells also receive dorsal molecular layer input and are also expected to inhibit pyramidal cells. Reduced parallel fiber activity can be expected to reduce the inhibition of the E-cells mediated by all three of these cell types. The polymorphic and granule cells also receive inputs from the receptor afferents, and this input is unaffected by manipulations of the dorsal molecular layer activity; therefore, some inhibitory input to the E-cells should remain after PET anesthesia or EGP lesions. Receptor afferents respond to stepwise increases in EOD amplitude with a very slowly adapting response, but the E-cells responded with an initial burst that always showed some degree of adaptation even when the input to the dorsal molecular layer was reduced (compare Fig. 2, $A$ and $B$ ). This early adaptation of E-cells could be due to the increased granule and polymorphic cell activity resulting from increased receptor afferent input.

\section{I-cell responses}

I-cells, nonbasilar pyramidal cells, respond to an increase in EOD amplitude with a decrease in firing frequency and, op- positely, to decreases in EOD amplitude. Both of these responses are accentuated when input to the dorsal molecular layer is removed or reduced. Removal of the excitatory parallel fiber input to the apical dendrites of the I-cells could contribute to the increased inhibitory response to increased electrosensory input. Removal of this input to the I-cells, however, cannot account for the increased responsiveness seen with decreases in EOD amplitude. The most direct explanation for the changes in I-cell responses involves changes in polymorphic cell inhibition of the granule cells and of the receptor afferents. The inhibitory axoaxonic synapse between the polymorphic cell and the receptor afferent terminal is expected to modulate the effectiveness of the receptor to granule cell synapse. Reduced polymorphic cell activity, as is expected from the reduced dorsal molecular layer input, should increase the effectiveness of this synapse, and this alone could account for the increased responsiveness of the I-cells to both increases and decreases in receptor afferent input. I-cells respond to increased reductions of electrosensory input with increasing responses up to reductions of about $200 \mu \mathrm{V} / \mathrm{cm}$ (Fig. 3B). Beyond this level, the responses plateau. EGP lesions not only increased the responsiveness of the I-cells, but this treatment also increased the plateau response size. This suggests that the EGP lesions must also affect the granule cells; they must be able to decrease their firing frequency by larger amounts before being silenced. Reduced polymorphic cell activity should release the granule cells from inhibition, and the resulting increased granule cell activity could encode larger decreases in afferent input before being silenced. This increased granule cell activity should also change the spontaneous firing frequency of I-cells; however, the average reduction in I-cell activity that was observed was small, as was the reduction in E-cell spontaneous activity that resulted from the removal of the input to the dorsal molecular layer. (See Note added in proof.)

\section{Spatial aspects of $E$ - and I-cell responses}

Maler et al. (1981) proposed that the receptive fields of the basilar and nonbasilar pyramidal cells are organized in a centersurround configuration. The E-cell receptive field center would be driven by receptor afferents that converged on its basilar and somatic dendrites from a small area of hody surface. The granule cells that project to a given E-cell lie in a disk centered on that 
E-cell, and the granule cells receive input from a larger region of skin because of their larger dendritic arbors. Hence, the excitatory region of an E-cell's receptive field should be surrounded by a region of opposite response. Similar mechanisms were proposed for I-cells. In this case, the receptive field center is driven disynaptically via a population of granule cells receiving input from a small area of skin. The surround would also be driven by granule cells, but those responsible for the surround would excite the I-cell via the electrotonic synapses that granule cells make exclusively with the nonbasilar cell.

Results of earlier experiments designed to estimate the extent of these proposed surround components of the receptive fields indicated that they were relatively weak, perhaps contributing to the sensitivity to target movement direction often seen in ELLL E- and I-cell responses (Bastian, 1981b). Removal of input to the dorsal molecular layer by either PET anesthesia or EGP lesions not only increased the excitatory response of E-cells to conducting targets and of I-cells to nonconducting targets, but also greatly enlarged regions of inhibition flanking the excitatory responses. These enhanced regions of inhibition cannot be solely due to larger postexcitatory rebounds, since the inhibition occurs on both sides of the excitatory response, i.e., before and after the excitation. The enlarged regions of enhanced surround could also be due to reductions in the activity of the polymorphic cells. The granule cells are probably involved in generating the surround responses for both types of cells, and any reduction in their inhibition, as is expected with removal of dorsal molecular layer input, should increase the intensity and, perhaps, the spatial extent of these surround regions. These results suggest that the dorsal molecular layer is also capable of modulating the extent of receptive field antagonistic surrounds.

These speculations are useful in that they generate predictions about the behavior of the ELLL interneurons in normal fish and in those having reduced input to the ELLL dorsal molecular layer. As yet, no recordings have been made from anatomically defined ELLL interneurons, from the EGP granule cells, or from the neurons of the $n$. praeeminentialis in gymnotiform fish. The $n$. praeeminentialis has been studied in catfish. The properties of these neurons suggest that they may integrate inputs from multiple categories of ELLL output neurons as well as inputs from mechanosensory systems (Tong, 1982). Further studies, using intracellular recording and single-cell marking techniques, will be necessary to determine the validity of these predictions about the behavior of ELLL interneurons.

\section{Functional significance of feedback connections to the ELLL}

Unlike many other acousticolateral systems, there is no efferent innervation to the electroreceptors; hence, gain control at the periphery is absent. This study shows that the gain of the electrosensory system can be controlled at the level of the first sensory processing station. At this time, however, we can only speculate as to which natural situations might cause the animal to make use of this descending control. The fish are nocturnal, and it may be useful for them to be able to increase the gain of the clcctrosensory system during their active phase, when they venture into open water. During the day they are often found in larger congregations among rocks or vegetation, and at this time the sensitivity of the system might be reduced in order to minimize the effects of the discharges of nearby conspecifics. Such changes would be expected to occur over the entire ELLLthe gain change would be global.

The amplitude of the EOD at a given region of the body can vary significantly as the animal changes its posture. Such selfimposed amplitude modulations of the EOD can alter the ability of the electrosensory system to respond to targets in the environment. This descending gain control might operate to stabilize the sensitivity of the system to relevant stimuli during such postural changes. In this case, we would expect the changes in gain to be different in different regions of the ELLL. The sensory input used to trigger such compensatory gain changes may be electrosensory, or perhaps proprioceptive. Cerebellar neurons sensitive to both electrosensory and proprioceptive inputs have been previously described (Bastian, 1974).

The ELLL is subdivided into four zones, three of which receive complete maps of the tuberous electroreceptor input, while the fourth receives input from the ampullary or low-frequency electroreceptors (Heiligenberg and Dye, 1982). The three tuberous ELLL subdivisions project to unique subdivisions of the n. praeeminentialis, and the outputs of these regions of the n. praeeminentialis ultimately feed back to the ELLL in a complex fashion. Output from a given region of the PED can project to portions of several of the subdivisions of the ELLL (Maler, personal communication). Therefore, it is possible that independent changes in the gain of portions of the ELLL subdivisions can occur. The roles of the three separate tuberous zones of the ELLL in analyzing electrosensory input are not yet understood. Having the ability to modulate the gain of portions of each of these independently might allow the animal to accentuate or attenuate selected features of the electrosensory input. Future studies of the feedhack connections to the EI.I.I. should concentrate on determining the cellular mechanisms by which this control is mediated, as well as the behavioral situations or the more natural patterns of electrosensory input that cause the animal to modulate the activity of this descending connection.

Note added in proof. Additional experiments and increased sample size show that EGP lesions cause statistically significant decreases in E-cell spontaneous activity (Bastian, in press).

\section{References}

Bastian, J. (1974) Electrosensory input to the corpus cerebelli of the high frequency electric fish Eigenmannia virescens. J. Comp. Physiol. 90: 1-24.

Bastian, J. (1975) Receptive fields of cerebellar cells receiving exteroceptive input in a gymnotid fish. J. Neurophysiol. 38: 285-300.

Bastian, J. (1981a) Electrolocation. I: An analysis of the effects of moving objects and other clectrical stimuli on the electroreceptor activity of Apteronotus albifrons. J. Comp. Physiol. 144: 465-479.

Bastian, J. (1981b) Electrolocation. II: The effects of moving objects and other electrical stimuli on the activities of two categories of posterior lateral line lobe cells in Apteronotus albifrons. J. Comp. Physiol. 144: 481-494.

Bastian, J. (in press) Gain control in the electrosensory system: A role for the descending projections to the electrosensory lateral line lobe. J. Comp. Physiol.

Bastian, J., and W. Heiligenberg (1980) Neural correlates of the jamming avoidance response in Eigenmannia. J. Comp. Physiol. 136: 135-152.

Bullock, T. H. (1982) Electroreception. Annu. Rev. Neurosci. 5: 121170.

Enger, P. S., and T. Szabo (1965) Activity of central neurons involved in electroreception in some weakly electric fish (Gymnotidae). J. Neurophysiol. 28: 800-818.

Heiligenberg, W. (1975) Theoretical and experimental approaches to spatial aspects of electrolocation. J. Comp. Physiol. 103: 247-252.

Heiligenberg, W. (1983) The jamming avoidance response in an electric fish: Algorithms in sensory information processing and their neuronal organization. In Advances in Vertebrate Neuroethology, J.-P. Ewert, D. Ingle, and R. Capranica, eds., pp. 669-699, Plenum, New York.

Heiligenberg, W., and J. Bastian (1984) The electric sense of weakly electric fish. Annu. Rev. Physiol. 46: 561-583.

Heiligenberg, W., and J. Dye (1982) Labelling of electroreceptive afferents in a gymnotoid fish by intracellular injection of HRP: The mystery of multiple maps. J. Comp. Physiol. 148: 287-296.

Hopkins, C. D. (1976) Stimulus filtering and electroreception: Tuberous electroreceptors in three species of gymnotoid fish. J. Comp. Physiol. 111: 171-207.

Hopkins, C. D. (1983) Functions and mechanisms in electroreception. In Fish Neurobiology, Vol. 1, R. G. Northcutt and R. E. Davies, eds., pp. 215-259, University of Michigan, Ann Arbor, MI. 
Hoshimiya, N., K. Shogen, T. Matsuo, and S. Chichibu (1980) The Apteronotus EOD field: Waveform and EOD field simulation. J. Comp. Physiol. 135: 283-290.

Maler, L. (1979) The posterior lateral line lobe of certain gymnotoid fish: Quantitative light microscopy. J. Comp. Neurol. 183: 323-364.

Maler, L., T. Finger, and H. J. Karten (1974) Differential projections of ordinary lateral line receptors and electroreceptors in the gymnotid fish, Apteronotus (Sternarchus) albifrons. J. Comp. Neurol. 158:363382.

Maler, L., E. Sas, C. E. Carr, and J. Matsubara (1982) Efferent projections of the posterior lateral line lobe in Gymnotiform fish. $\mathbf{J}$. Comp. Neurol. 211: 154-164.

Maler, L., E. K. B. Sas, and J. Rogers (1981) The cytology of the posterior lateral line lobe of high frequency weakly electric fish (Gym- notidae): Dendritic differentiation and synaptic specificity in a simple cortex. J. Comp. Neurol. 195: 87-140.

Sas, E., and L. Maler (1983) The nucleus praeeminentialis: A golgi study of a feedback center in the electrosensory system of gymnotid fish. J. Comp. Neurol. 221: 127-144.

Saunders, J., and J. Bastian (1984) The physiology and morphology of two types of electrosensory neurons in the weakly electric fish Apteronotus leptorhynchus. J. Comp. Physiol. 154: 199-209.

Scheich, H. (1977) Neural basis of communication in the high frequency electric fish, Eigenmannia virescens (jamming avoidance response). J. Comp. Physiol. 113: 181-255.

Tong, S. (1982) The nucleus praeeminentialis: An electro- and mechanoreceptive center in the brainstem of the catfish. J. Comp. Physiol. 145: 299-309. 